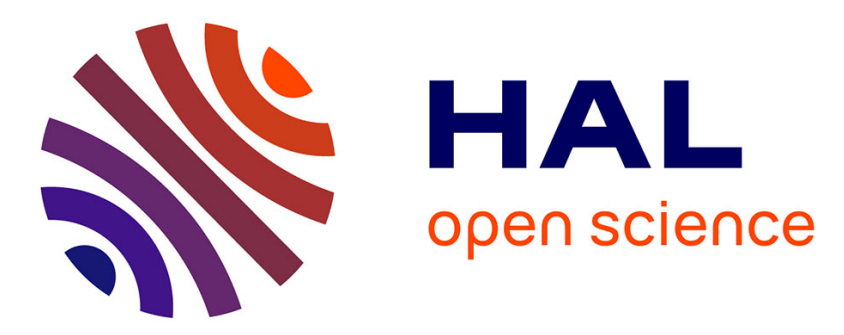

\title{
Discussion: Comments on "Basalt columns: Large scale constitutional supercooling? by John Gilman (JVGR, 2009) and presentation of some new data [J. Volcanol. Geotherm. Res. 184 (2009), 347-350] Bernard Guy
}

\section{To cite this version:}

Bernard Guy. Discussion: Comments on "Basalt columns: Large scale constitutional supercooling? by John Gilman (JVGR, 2009) and presentation of some new data [J. Volcanol. Geotherm. Res. 184 (2009), 347-350]. Journal of Volcanology and Geothermal Research, 2010, 194 (1-3), pp.69-73. 10.1016/j.jvolgeores.2009.09.021 . hal-00493003

\section{HAL Id: hal-00493003 https://hal.science/hal-00493003}

Submitted on 17 Jun 2010

HAL is a multi-disciplinary open access archive for the deposit and dissemination of scientific research documents, whether they are published or not. The documents may come from teaching and research institutions in France or abroad, or from public or private research centers.
L'archive ouverte pluridisciplinaire HAL, est destinée au dépôt et à la diffusion de documents scientifiques de niveau recherche, publiés ou non, émanant des établissements d'enseignement et de recherche français ou étrangers, des laboratoires publics ou privés. 


\title{
Discussion: Comments on "Basalt columns: Large scale constitutional supercooling? by John Gilman (JVGR, 2009) and presentation of some new data [J . Volcanol. Geotherm. Res. 184 (2009), 347- 350]
}

\section{BERNARD GUY*}

Ecole Nationale Supérieure des Mines de Saint Etienne, Centre SPIN ; Département GENERIC, 158 Cours Fauriel ; 42023 Saint-Étienne Cedex 2, France

\begin{abstract}
Some comments are offered on the paper by J ohn J . Gilman (J . Volc. Geoth. Res., 184, 2009, 347-350), proposing that large scale constitutional supercooling may explain the formation of basalt columns. This hypothesis was presented twenty years ago (Guy, B. and Le Coze, J., C. R. Acad. Sc. Paris, 311, II, 1990, 943-949). However, in contrast to what is postulated by Gilman, I proposed that the chemical variations that may (optionally) show in the prisms do not relate to the major elements $\left(\mathrm{Al}, \mathrm{Si}\right.$, ...) but rather to $\mathrm{H}_{2} \mathrm{O}$ and other volatiles. Thermal contraction, which is the more generally accepted hypothesis, also plays a role, particularly in the central "entablature" of the flows. The fingers formed by constitutional supercooling show instead in the colonnades. Original observations are presented that support the hypothesis of supercooling, in particular the existence of circular and radiating structures within the columns, that cannot be explained by meteoric weathering nor by the influence of the fractures delimiting the prisms. Various directions for research are proposed.
\end{abstract}

Keywords:

basalt; columnar jointing; constitutional supercooling; thermal contraction; circular structures

\section{Introduction}

I have read with interest the paper by J ohn J . Gilman presenting a new hypothesis to explain columnar jointing of volcanic rocks: Basalt columns, large scale constitutional supercooling? (J. Volcanol. Geotherm. Res., 184, 2009, 347-350). I have myself proposed a similar hypothesis nearly twenty years ago: Reflections on columnar jointing of basalts: The instability of the planar solidification front (Guy B. and Le Coze J., C. R. Acad. Sc. Paris, 311, II, 1990, 943-949). While I agree that constitutional supercooling has the major role in explaining the formation of basalt columns, it seems to me to-day that thermal contraction of a homogeneous solid mass (the explanation commonly adopted) is not to be excluded. Some details of the proposal by J .J . Gilman (2009) must also be discussed. In order to support my comments, several personal observations obtained during the past twenty years are included. Bibliographic references cited are just related to the few points discussed here, and do not pretend at all to present an even partial panorama on the subject (see a more complete bibliography in cited articles).

\section{Behavior of the chemical elements during solidification}

The constitutional supercooling mechanism will produce chemical composition gradients during solidification; these may or may not show in the final solid, that is to say between the centre and the rim of the basalt column. The possible mineralogical and chemical variations

\footnotetext{
*Auteur à qui la correspondance devait être adressée : guy@emse.fr
} 
are generally overlooked by the authors in the literature, because they are not expected in the hypothesis of the thermal contraction of a homogeneous solid. However, if some examples do show chemical and mineralogical contrasts (see references in Guy and Le Coze, 1990), they are rare and small. They do not have the magnitude postulated by J J . Gilman when he speaks of minerals with a high solidification point, such as aluminates, expected at the centre of the prisms, and minerals with a low solidification point, such as silicates, expected at the rim; such disparities are not observed in the prisms.

Actually, if one compares the composition of a basaltic liquid with the solid or, as noted by J . Gilman, with the glass resulting from it, the only (or almost the only) observed differences relate to water and various other volatile contents $\left(\mathrm{CO}_{2}\right.$, sulphur-bearing gases, etc.). Therefore, it is useful to support the discussion from the theoretical point of view by constructing phase diagrams involving volatiles, and also, in addition to solid and liquid phases, involving glass and the glass transition, and so to involve kinetics. Research work is needed. The difficulty is also that the solid phase comprises several minerals (and not one as in the case of metals): olivine, pyroxenes, magnetite, feldspars.... We must consider the extension of the thermodynamic model to a collection of minerals, or see how to treat the whole solid as a single mineral, since the solid phase actually has a collective behavior. As a first step one can restrict to the feldspar, for example the anorthite (melt/solid/glass), assuming that the other minerals have already precipitated or do not play a role in the finishing solidification. Then, the influence of water on the corresponding phase diagrams must be studied. Considering the rock analyses, some authors such as Ildefonse (1987) examined the presence of water that can be marked by an early self-weathering at the prism periphery, and that must carefully be distinguished from subsequent weathering by waters external to the initial magma. The discussion of possible differences in composition (including $\mathrm{H}_{2} \mathrm{O}$, etc.), between the centre and the periphery of the prisms, is delicate because one can always invoke the action of external waters flowing through the rock along the joints between the basalt columns. Note that, in the constitutional supercooling model, the liquid composition differences may not be disclosed in the solid, depending on the shape of the phase diagram (in particular the solidus). In our problem, water and other volatiles may be completely expelled from the system virtually without leaving any imprint in the solid.

\section{Preferential fracturing along the joints drawn by constitutional supercooling}

The geometry of the joints is the first argument given by J J . Gilman to refute the hypothesis of thermal contraction. This must also be discussed. In the contraction phenomenon, one obtains polygons with $90^{\circ}$ angles present in the dominant proportion, with possible concave contours (and the joints may open) (Figure 1); whereas in the constitutional supercooling phenomenon, other polygons, always convex, are obtained, in particular hexagons with $120^{\circ}$ angles (and joints may remain shut) (Figure 2). The networks are quite different, and the second one does correspond to the standard basaltic columns. But we must stress that the two types of geometries are observed in basaltic columns and that thermal contraction may play a role to a certain extent. In particular it may do so for thin magma flows (or in the external, chilled, part of the flows) where very strong thermal gradients impede supercooling, and where the solidification front remains planar and advances very quickly. At the other extreme, it may do so in the "entablature" observed inside thick flows. There, low thermal gradients (lower than on the borders of the flow) give rise to large supercooling and allow nucleation of solid to occur within the liquid. Solidification will take place from the bulk (and not from the solid fingered walls), and subsequent contraction will take place without early fingering. The thermal contraction also plays a part in the case of cooling volcanic rocks that did not have a liquid stage such as some welded tuffs or ignimbrites. Eventually, thermal contraction can cross-cut the prisms that were created by the supercooling phenomenon. On the other hand, the standard hexagonal networks are mostly observed within the colonnades. On these points, further work still must be conducted to study the characteristics of the two types of 
joint/crack networks, their occurrences and relationships. In the literature on the subject, some authors recognize that networks due to contraction are actually different from those commonly observed in basalt columns, but argue that they just appear at the surface and can become more regular at depth and become similar to those of the latter. Theoretical models are proposed (see e.g. Saliba and J agla, 2003). These works deserve thorough attention, but do not appear to me as supporting the contraction hypothesis, since the chosen geometry of the starting point itself does not match with this hypothesis; and because the model predicts an equilibration of the dimensions of the polygons at depth and not the appearance of new angles between the joints, that would be needed to shift from one system to the other. Experimental work on drying starch, although it actually shows an ordering of fracture networks in depth, does not lead to a hexagonal-type geometry strictly similar to that of the rocks (see e.g. Toramaru and Matsumoto, 2004). When one speaks of a transition between one system to the other on the field, this is likely to be merely a juxtaposition between a thermal contraction network outside and a supercooling fingering network inside the flow.

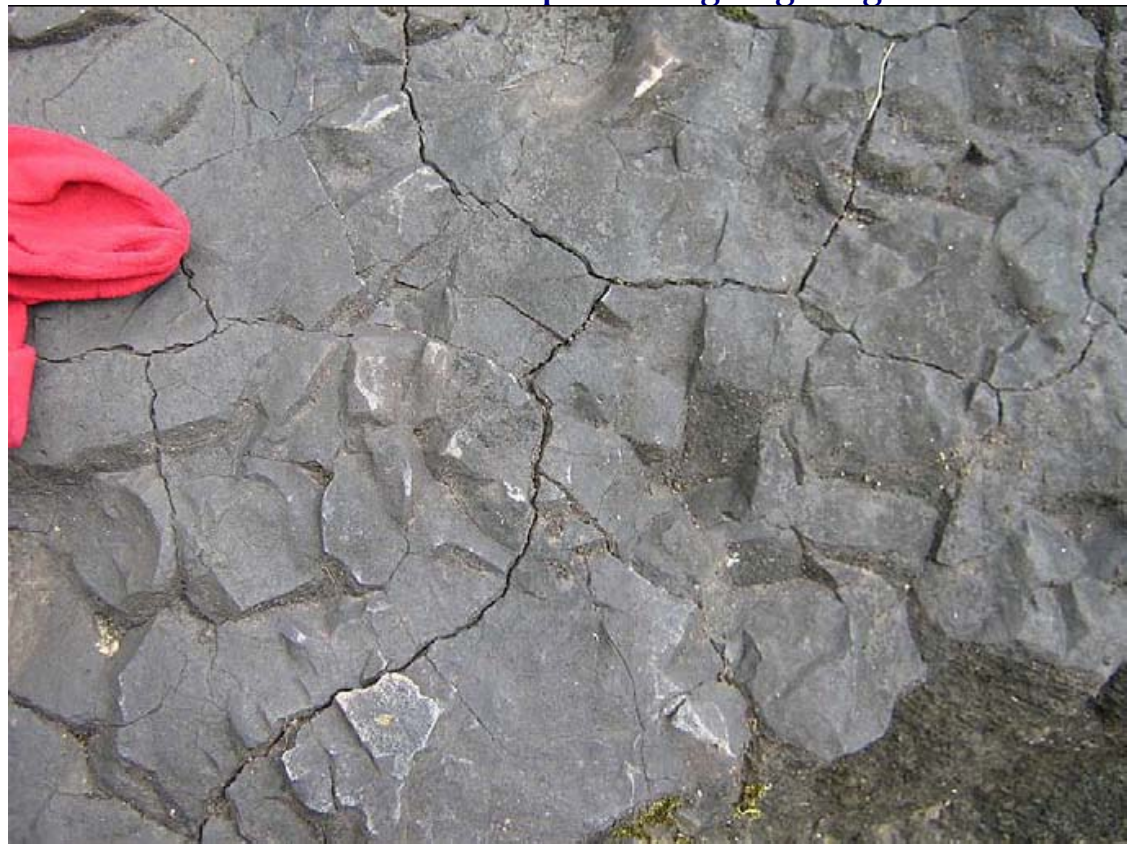

Figure 1: Geometry of fractures and joints in an entablature. Saint-Arcons, Haute-Loire, France. The size of the polygons varies from 10 to $20 \mathrm{~cm}$. According to our analysis, this type of network is due to thermal contraction (see text).

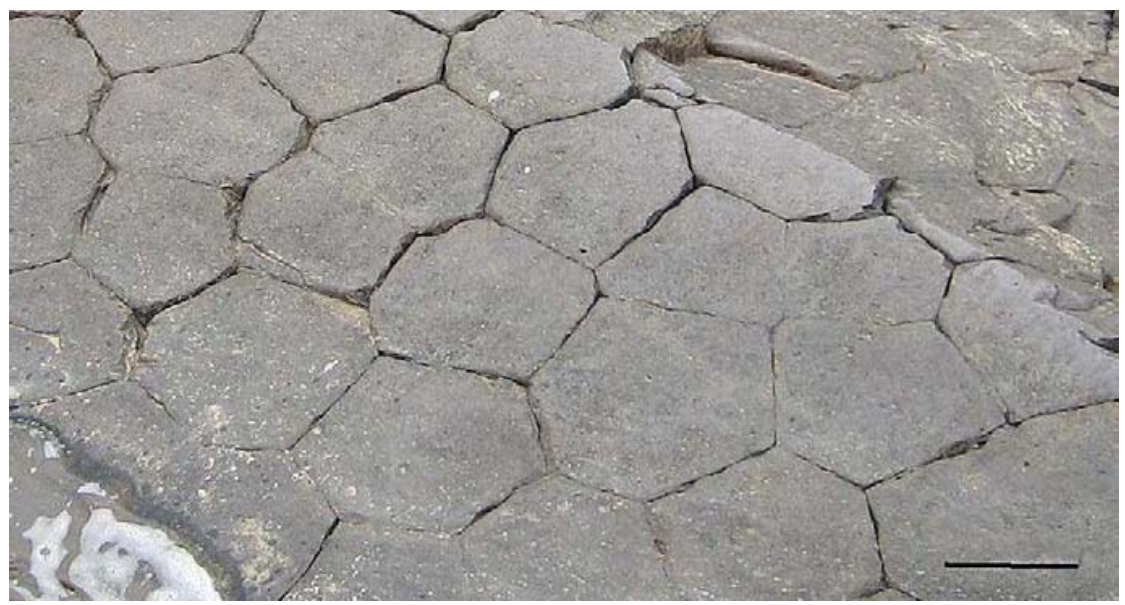

Figure 2: Geometry of fractures and joints in a lower colonnade. Aubrac, France. According to our analysis, this type of network is due to supercooling fingering (see text). The size of the polygons is $40-50 \mathrm{~cm}$ (scale bar length: approx. $30 \mathrm{~cm}$ ). 
Within the constitutional supercooling model, J J. Gilman postulates that the fracturing can occur along the previously developed joints which would be more fragile. But it remains to be demonstrated that the mechanical properties of rocks with a higher content of water and/ or glass actually allow easier fracturing (therefore it is not the contrast between the silicate and aluminate mechanical properties which is important, as proposed J.J. Gilman). Generally speaking we know that materials with lower melting points have lower elastic limits, and the joints would be then more fragile anyway. It still should be noted that, in the case of hexagonal structures, joints can be welded and so not give rise to a real fracturing by opening. Beyond topology differences between various fracture networks, it is necessary to discuss the possible wavelengths and explain how one goes from the micron or tens of micron size of metallic alloys to the decimetre size of geology. J.J. Gilman gives a list of intervening parameters (speed of solidification, diffusion coefficients etc.). In Guy and Le Coze, 1990 we compared both cases and showed that the major difference is the much lower thermal gradients in the case of the geology as compared to metallurgy. Thanks to semi-quantitative formulae proposed by metallurgists we showed that we can go back to the dimensions observed for the volcanic rocks. When thermal contraction comes into play, the wavelengths are smaller than that of the neighbouring supercooling fingers.

\section{Existence of circular structures prior to thermal contraction}

Before one gets further quantitative data on the thermodynamics, kinetics and mechanics of complex silicate systems (including solid, liquid and glass and various proportions of volatiles) as just discussed, let us remain more qualitative, and let us stress the following: if one takes the constitutional supercooling hypothesis for granted, some circular structures within the cells are to be expected; they reveal heterogeneities of the solid mass before its possible thermal contraction, and are related to degassing. These heterogeneities are rare; in order to be registered in the solid, they must freeze a rapid change in the composition and the properties of the magma around the finger that did not have time to be erased by diffusion within the liquid. In the past twenty years, I have sought such heterogeneities and have found many. I give some examples here without discussing the details of the mechanisms involved for each.

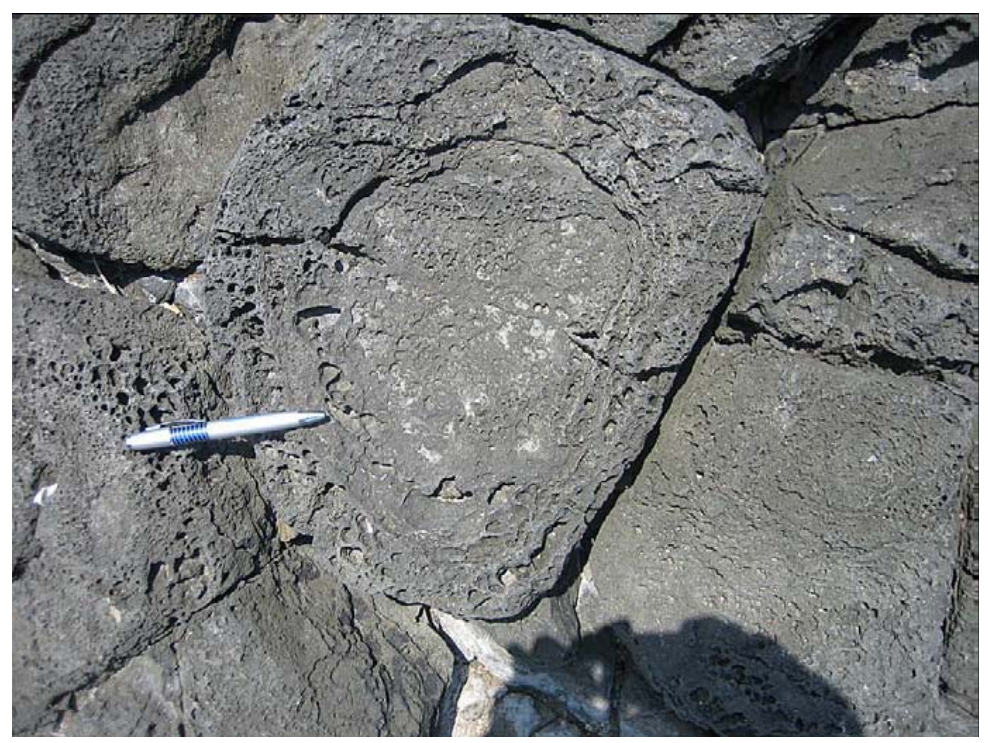

Figure 3: Basalt prism section showing a cylindrical distribution of gas bubbles. Cap Nègre, near Sanary sur mer, Var, France.

\section{IV.1. Bubble circles}

In Figure 3, bubble circles are parallel to the rims of the prisms. The size and abundance of bubbles draw contours that cannot be formed within one previously homogeneous solid mass undergoing fracturing, even if there is a remaining proportion of liquid. The bubbles observed 
at the periphery of the cells testify a gas enrichment of the liquid around fingering solid that either accepts no gas or very little.

\section{IV.2. Radiating structures within circular structures}

The radiating and circular structures are revealed by slight texture (and not composition) differences (size, shape and orientation of grains, alignments of grains, abundance of glass) enhanced by meteoric weathering. In [Figure 4] and [Figure 5] one can see that the central part of the basalt column is a little raised, as compared to the peripheral part that is more flat. The transition between the two parts is relatively sharp and draws a more or less perfect circle. Such structures have been observed at Giant's Causeway, Ireland, and in Iceland (Skaftafell Park). Radiating from the centres of the circles, corresponding to those of the prisms, rays are visible and define more or less well marked lines. The radiating structures cannot be explained by a fracturing phenomenon. The fracturing imprints would then have no reason to start from the centre, but from some point on the rim, as it may sometimes occur when fracturing does come into play. And why would radiating structures, that supposedly show the progress of fracturing, stop along a more or less perfect circle? If one invokes the fracturing of the different prism edges as a cause to create the circles, a perfect synchronization of these fractures should be needed in order to have a circular symmetry for both rays and outline boundary; authors speak instead of successive fractures. How then could each fracture occurrence influence a particular sector, without touching the other, in such a way that all sectors ultimately draw a structure with cylindrical symmetry? Radiating structures are also not explained by late meteoritic weathering. In our view on the contrary, the explanation of the radiating structures well matches with the constitutional supercooling hypothesis: a directional growth of minerals takes place as guided by the geometry of the solid fingers. If during the subsequent evolution involving temperature decrease, some threshold similar to a eutectic or a peritectic on a phase diagram is arrived at, it may give a sudden change (provisional gas unmixing for example) that modifies the texture of the solid crystallizing from the melt and that may be marked within circular rock structures.

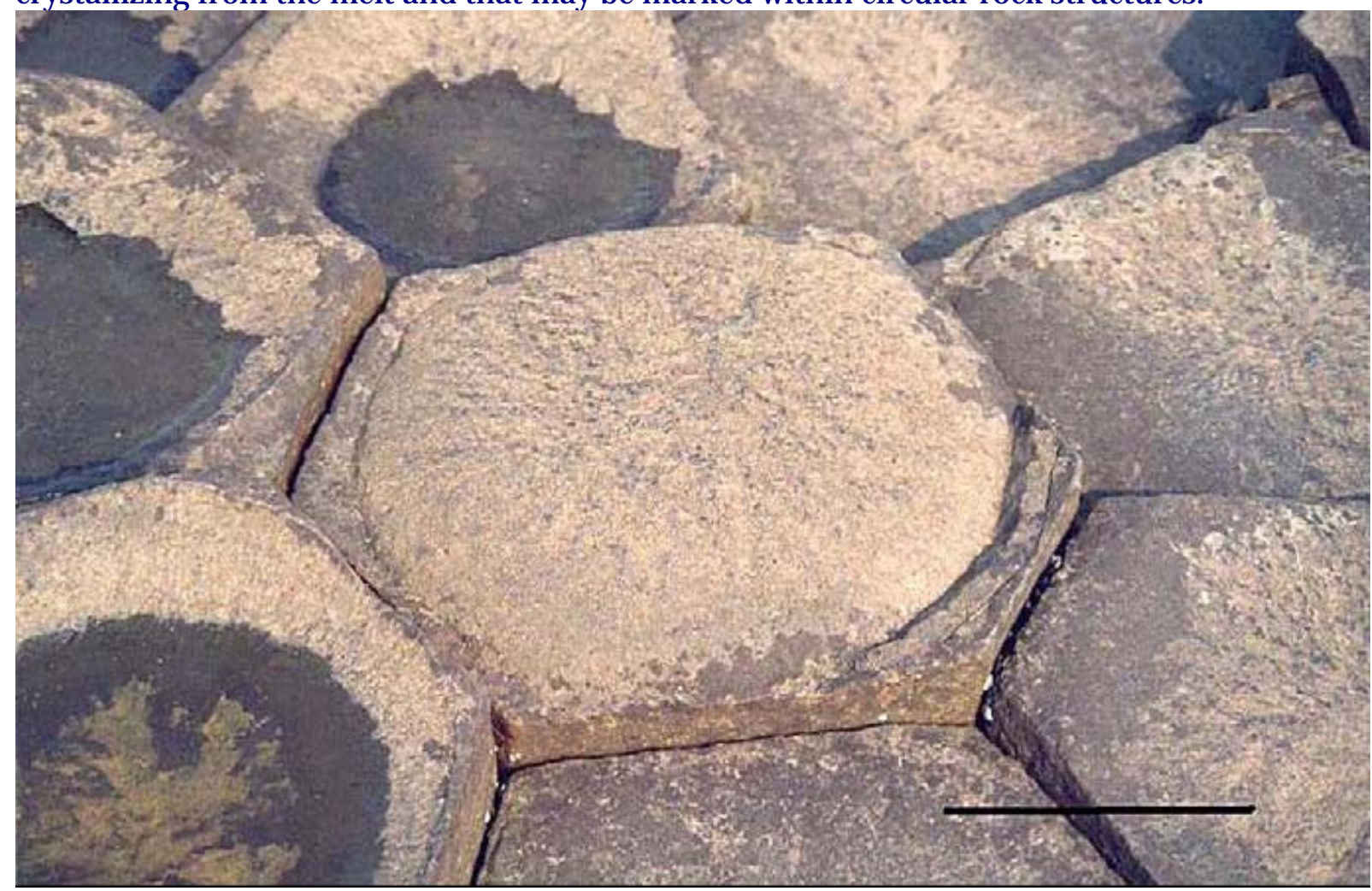

Figure 4: Basalt prism section showing a radiating structure limited by a circle. The circle is itself inscribed within the polygonal section. Giant's Causeway, Ireland. Diameter of the prism of about $60 \mathrm{~cm}$ (scale bar length: approx. $25 \mathrm{~cm})$. 


\section{IV.3. Circular structures within the prisms, circular structures cross-cut by the edges of the prisms}

Let us have a closer look to the previous circular structures that appear as black rings on fresher rock sections ([Figure 6], [Figure 7], and [Figure 8]). The formation of these rings cannot be explained within the hypothesis of a homogeneous solid mass contraction, by a weathering process starting from the prism edges. The centre of the rings may be shifted with respect to the edges of the prisms: in some places the ring is very close to the edge (a few millimetres), in other places much farther away. The computer simulation of a diffusion process starting from the polygonal (hexagonal) external boundary shows that if the ring is close to the edge somewhere, it should be expected to be close to the other edges. We also observe unexpected morphologies for weathering rings that would initiate from the edges: concavity changes and scalloping. One observes a gradient in the intensity of the ring (black) color that is directed to the outside. If the ring was made from the edge, the gradient should be the reverse of this. Finally an argument which seems essential is that the circular structures can be cross-cut by prism edges (Figure 8). From the principles of relative chronology, we simply conclude that what is cross-cut is earlier than what cuts, that is to say the circle is prior to the fracturing delimiting the edges of the prism. The explanation of such circles cut by prism joints may be found by considering the welding of two neighbouring prisms into one, as may sometimes be observed in the field and in the case of the solidification of metal alloys (e.g. Wolczynski, 2002). Rings resulting from an oxidation process of external origin may be observed, but they have different colors (more brown or orange), their geometries are different (e.g. repeated circles of Liesegang type) and show in thin section oxides that are lacking in black rings. The two types of rings can coexist; they can overlay and overlap as is the case for the black ring intersected by the edges of the prism discussed just before (the edge ring is marked by an oxidizing weathering of external origin).

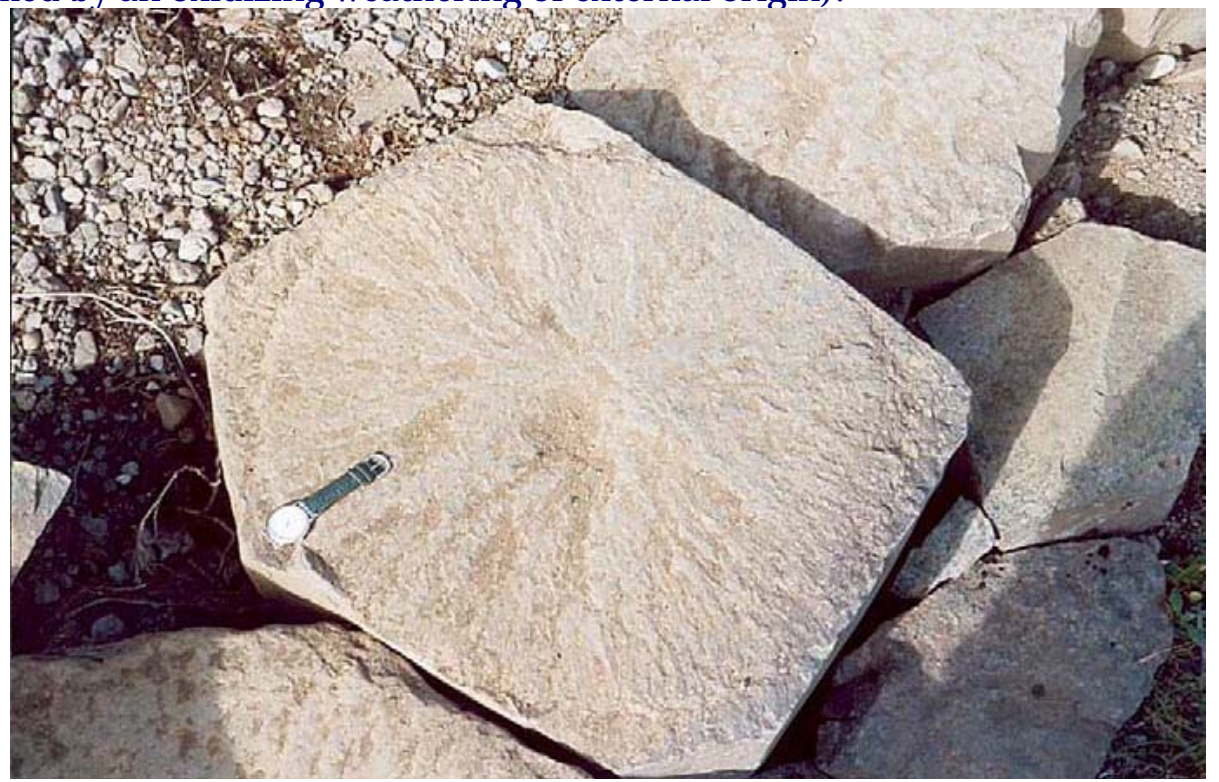

Figure 5: Basalt prism section showing a radiating structure limited by a circle. The circle is itself inscribed within the polygonal section. Skaftafell Park, Iceland.

\section{IV.4. Circular structures revealed by anisotropy of magnetic susceptibility (AMS)}

Analysis of magnetic susceptibility anisotropy (AMS) provides information on the size, shape and orientation of mineral grains, and the existence and orientation of grain alignments. We see in the literature (for example Ellwood and Fisk, 1977) that the texture as revealed by AMS may vary between inside and outside the sections of the prisms and may, when we map them, draw circular structures that penetrate to the centre of the prisms. How could the interpretation by contraction account for these results? In this standard explanatory 
framework, authors are forced to declare that the fracturing of the cell edges led to a reorientation or rotation of the rock minerals.

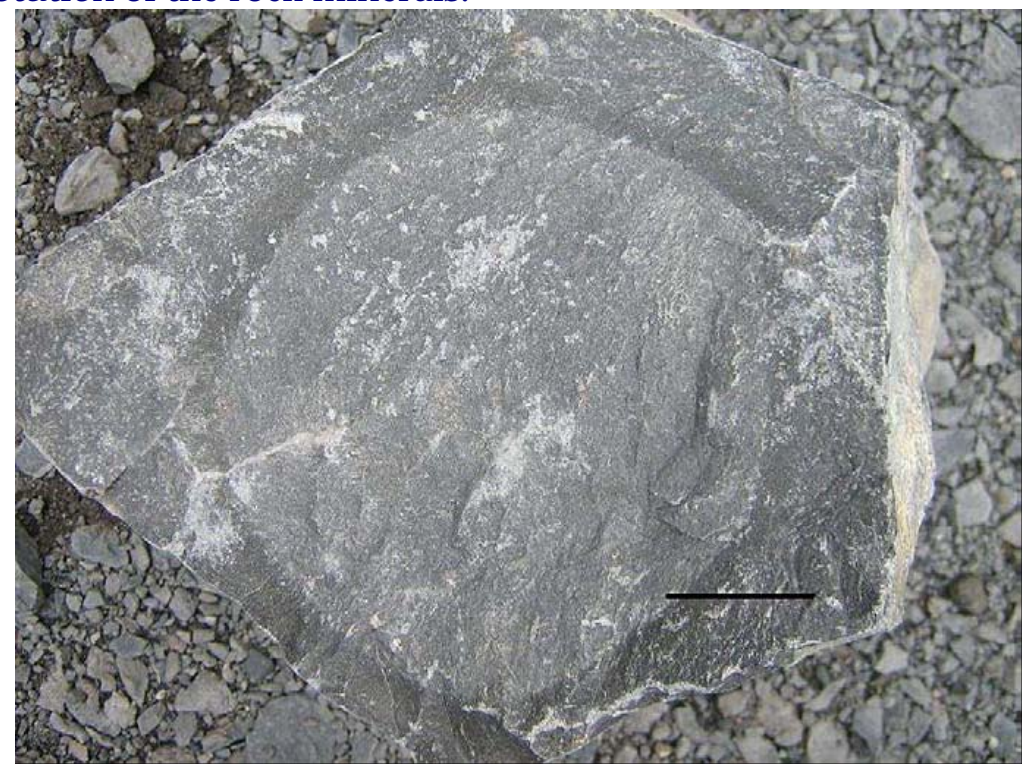

Figure 6: Black ring inscribed within one basaltic prism section. Saint-Arcons d'Allier, Haute-Loire, France. In this figure and the following two, the diameter of the prism is between 20 and $30 \mathrm{~cm}$; the width of the black bands is approximately $5 \mathrm{~mm}$ to $1 \mathrm{~cm}$ (scale bar length: approx. $5 \mathrm{~cm}$ ).

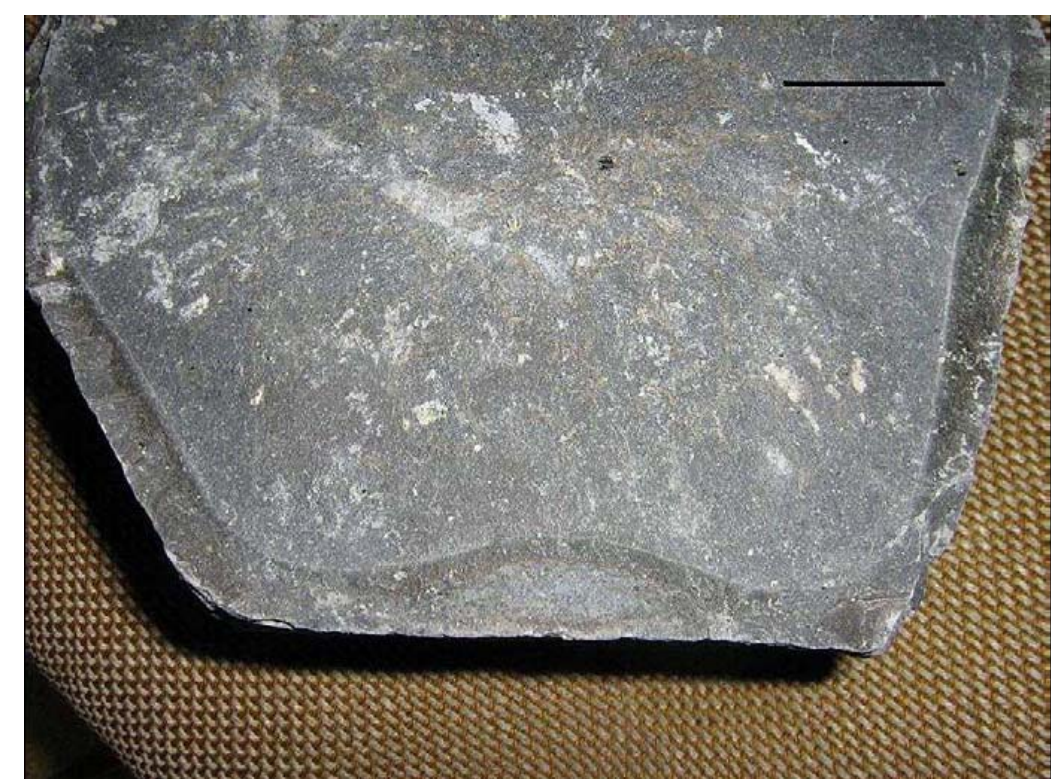

Figure 7: Black ring inscribed within one basaltic prism section. Saint-Arcons d'Allier, Haute-Loire, France (scale bar length: approx. $5 \mathrm{~cm}$ ).

In order for there to be fracturing, it is necessary that the rock subject to mechanical stresses behaves as a solid, provided the proportion of liquid is not excessive. Within the understanding where (successive) fracturings of the edges of the prisms would be responsible for orientation or re-orientation of the minerals of the rock, the details of this scenario should be examined: it assumes that the fracturing of an edge changes the orientation of minerals or imposes it only in a particular sector, so that the effects of a differently oriented fracturing may influence another sector (without changing the first). So that, in the end, the orientations have the observed circular symmetry (this is the same discussion as for former circular patterns). As we can see, such a scenario appears highly problematic, not to mention the question of how the solid rock minerals could rotate as a result of the adjacent edge fracturing. On the contrary, the circular patterns as seen by AMS are best explained by the 
development of fingers and the early preferential orientation of the solid grains as imposed by the fingers and to texture changes in parallel to gas content changes. This reinforces the previous results.

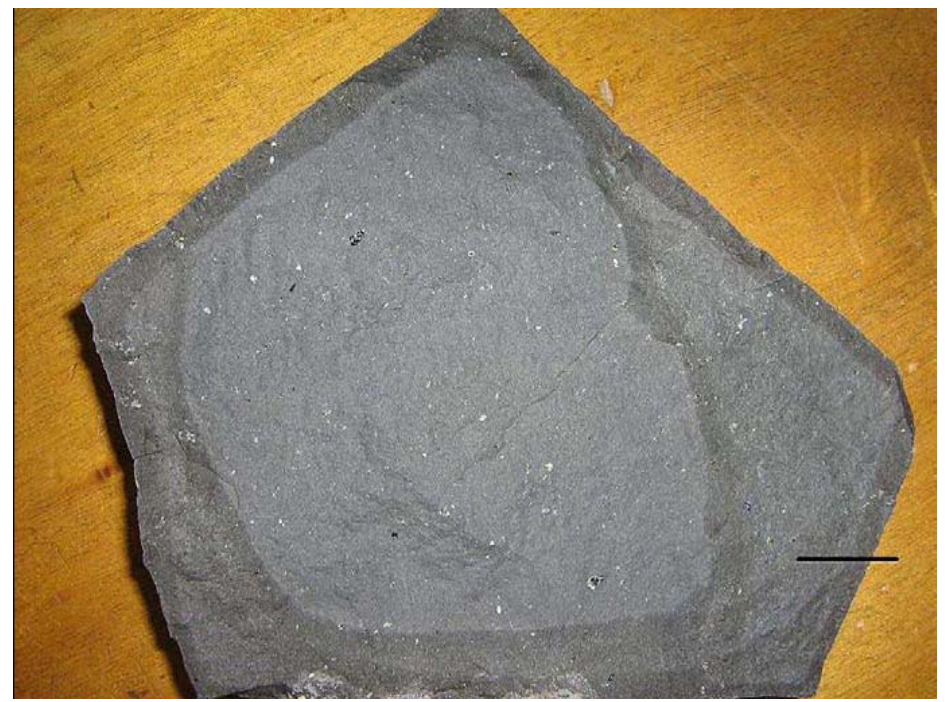

Figure 8: Black ring inscribed within one basalt section and intersected by the contours of the prism. SaintArcons d'Allier, Haute-Loire, France, (scale bar length: approx. $5 \mathrm{~cm}$ ).

\section{Discussion on large scale structures}

We could also discuss many lines of evidence dealing with structures at larger scales within the flows, and that favour the constitutional supercooling model. In particular, the existence of three parts within thick flows (lower colonnade, entablature, upper colonnade) which cannot be explained by propagation of contraction fractures. Some authors (e.g. Long and Wood, 1986) invoke influxes of water inside the flows that could induce a cooling of the rock independent of the outside border of the flow, and leading to the entablature. But they confess their perplexity at the existence of such entablatures in desert climates where scarce water is available. This assumption does seem ad hoc to me. And how one can explain the changes in the prism orientations? In the frame of the supercooling model instead these different characters are well understood: the internal zone of the entablature corresponds to a higher constitutional supercooling because of thermal gradients that are much smaller, and that are poorly oriented. This can lead to possible fingering in some anarchic directions, not related to the geometry of the borders of the flows; or to a solidification in the bulk with no fingering, followed by a thermal contraction as I outlined above. The understanding of the distribution of more glassy facies and more weathered zones (encountered in both the entablature and on the rims of the prisms) connects to the above statement: higher water content in the residual liquid promotes glass formation and allows a more intense self-weathering.

Many other features observed at the scale of the flows may also be studied; in Guy and Le Coze (1990) we reported the existence of areas with planar cells neighbouring the ordinary elongated cells (prismatic columns); they correspond to bifurcations observed and studied in the case of alloys and are not explained by the model of thermal contraction. The alternations of several colonnades and entablatures (or the irregularity of colonnade/ entablature contact) may also be understood within the supercooling model and related gas pressure variations.

\section{Conclusions}

Here I have rapidly covered a very rich subject, without considering all points of interest. I did not speak about the fabric imposed by the flowing of the magmas before their solidification and their cooling. Neither did I speak about the "schistosities", nor about the fracturings perpendicular to the directions of the prisms, and their relationship with other features (possible formation of bands on the surfaces of the prisms); I did not mention the presence of 
prisms inside the "magmatic rocks", or so called "paralavas" resulting from the melting of mining dumps! All these examples support the previous discussion. When comparing the two extreme hypotheses, it is important to examine all characters at all scales, and not only one. As a conclusion to this brief synopsis, it then appears clear to me that the constitutional supercooling hypothesis (as independently proposed by Guy and Gilman) has a high explanatory power. But it is not alone, and thermal contraction has its part, certainly more limited than accepted until now. It remains that the characteristics of this first hypothesis must be supported by theoretical work and that many studies must be conducted in order that the many remaining questions are enlightened.

\section{Acknowledgements}

The studies conducted by the author for twenty years and discussed here are extended by a $\mathrm{PhD}$ thesis project by Tiphaine Boiron addressing geochemical analyses (major and trace elements, stable isotopes), study of structures (as due to flow, fingering, contraction) by anisotropy of magnetic susceptibility (AMS) at different scales (from mineral to prisms and flows) and further characterization of materials by different analytical techniques (EBSD, DRX etc.). The Saint-Arcons site from which several photos are shown here is one of the sites being studied by Tiphaine Boiron This work is made in collaboration and dialogue with many people and particularly with: Jerôme Bascou, Eric Ferré, Marie-Christine Gerbe, Ariel Provost, Pascal Richet, Pierre Boivin, Casimir Cortial, René Fillit, Eric Touboul, Waldemar Wolczinski and Claire Guy, to whom we are grateful. I sincerely thank Prof. L. Wilson (Lancaster University, U.K.) for his assistance in editing the present paper, and especially for improving the English wording.

\section{References}

B.B. Ellwood, Anisotropy of magnetic susceptibility variations in Icelandic columnar basalts, Earth and Planetary Science Letters 42 (1979), pp. 209- 212.

B.B. Ellwood and M.R. Fisk, Anisotropy of magnetic susceptibility variations in a single Icelandic columnar basalt, Earth and Planetary Science Letters 35 (1977), pp. 116- 122.

J .J . Gilman, Basalt columns, large scale constitutional supercooling?, J ournal of Volcanology and Geothermal Research 184 (2009), pp. 347- 350.

B. Guy and J . Le Coze, Reflections on columnar jointing of basalts: the instability of the planar solidification front, Comptes rendus de l'Académie des sciences Paris 311 (II) (1990), pp. 943-949.

Ildefonse, P., 1987. Analyse pétrologique des altérations prémétéoriques et météoriques de deux roches basaltiques (basalte alcalin de Belbex, Cantal, et hawaïte de M'Bouda, Cameroun). Thèse Doctorat èt Sciences, Université Paris VI, 320 pp.

P.E. Long and B.J. Wood, Structures, textures, and cooling histories of Columbia River basalt flows, Geological Society of America Bulletin 97 (1986), pp. 1144- 1155.

R. Saliba and E.A. Jagla, Analysis of columnar joint patterns from three-dimensional stress modelling, J . Geophys. Res. 108 (B10) (2003), p. 24767 pp.

A. Toramaru and T. Matsumoto, Columnar joint morphology and cooling rate: a starch-water mixture experiment, J ournal of Geophysical Research 109 (2004), p. B02205 10 pp.

W. Wolczynski, Effect of the Back-diffusion onto Doublet Structure Formation and Solute Redistribution within Alloys Solidifying Directionally, with or without Convection, Polish Academy of Sciences, Institute of Metallurgy and Materials Science, Krakow (2002) 64 pp. 